Article

\title{
Phenolic and Theobromine Contents of Commercial Dark, Milk and White Chocolates on the Malaysian Market
}

\section{Cheng Chia Meng, Abbe Maleyki Mhd Jalil and Amin Ismail *}

Department of Nutrition and Dietetics, Faculty of Medicine and Health Sciences, Universiti Putra Malaysia 43400, UPM Serdang, Selangor Darul Ehsan, Malaysia; E-mails:

chiaming_peace@yahoo.com (C-C.M.), maleyki@yahoo.com (A-M. J.)

* Author to whom correspondence should be addressed; E-mail: amin@medic.upm.edu.my.

Received: 14 October 2008; in revised form: 3 December 2008 / Accepted: 8 December 2008 / Published: 5 January 2009

\begin{abstract}
Chocolate contains a wide range of antioxidants that includes soluble phenolic compounds (phenolic acids, catechin, epicatechin, and proanthocyanidins), insoluble polymeric phenolics and methylxanthines. The objective of this study was to determine phenolic and theobromine contents in dark (DC), milk (MC), and white (WC) chocolates commonly found in the Malaysian marketplace. Total phenolic and flavonoids were determined by means of a spectrometric assay, while catechin, epicatechin and theobromine were quantified using a reverse-phase HPLC method. Dark chocolates exhibited the highest phenolics and flavonoids contents, followed by milk and white chocolates. Catechin and epicatechin were major flavonoids detected in dark chocolates. Theobromine was detected in dark and milk chocolates, but not in white chocolates. A high correlation $(r=0.93)$ between total phenolic and flavonoid contents, indicating that the major phenolic compounds in dark chocolates belong to the flavonoid class. When nutrition and health promotion are of concern, dark chocolates would be recommended over milk and white chocolates owing to their higher contents of antioxidant phenolic compounds.
\end{abstract}

Keywords: Chocolates; Catechin; Epicatechin; Theobromine. 


\section{Introduction}

The antioxidant properties of cocoa polyphenols have generated great interest in their potential health benefits. Epidemiological studies have shown that polyphenols may help to reduce the risk of cardiovascular diseases [1-2]. Previous in-vivo studies revealed that cocoa products may have the potential to decrease the risk of degenerative diseases [3-6]. A meta-analysis of randomized controlled trials showed that the intake of cocoa-rich foods may reduce blood pressure [7]. Recently, an on-going cohort study of the Moli-sani Project revealed that regular consumption of small amounts dark chocolate may have helped reduce serum C-reactive protein levels in healthy Italian subjects [8].

Cocoa contains a wide range of antioxidants, which includes soluble phenolic compounds and insoluble polymeric phenolics [9]. Cocoa bean is one of best known sources of dietary polyphenols, which comprise on average $12-18 \%$ of total weight on a dry basis [10]. Generally, cocoa contains significant amount of procyanidin monomers, namely catechin, epicatechin and dimer to tetradecamer [11-16].

Methylxanthines, such as caffeine, theobromine, and theophylline, are consumed daily in a variety of foods, beverages, and pharmaceutical products. Generally, theobromine is a caffeine metabolite [17]. It had been noticed that its major dietary sources are from chocolate foods and beverages [18]. Caffeine and theobromine are psychoactive compounds, but the pharmacologically active constituents responsible for certain mood changes and related effects of chocolates have not been tested [19]. Several studies have been reported on the theobromine content of some chocolate products, for example, hot chocolate [20,21], chocolate milk [20, 22] and cocoa powder [20, 23]. Limited information on methylxanthine contents of Malaysian manufactured chocolates has been published $[24,25]$.

Chocolates may have different percentages of cocoa liquor, cocoa powder, cocoa butter, sugar, and milk powder used in making the different types of chocolates, namely dark, milk and white chocolates. The content of polyphenols and methylxanthines can vary depending on the source of beans (growing conditions and cocoa variety), processing conditions during fermentation and drying, and the chocolate making process. Alkalization (or dutching) of cocoa powder will influence the polyphenol [14, 26] and methylxanthine contents [23]. Due to these factors, the ratio and types of these components found in cocoa beans are unlikely to be the same as those found in the finished products [27].

Bittersweet chocolates, or so-called dark chocolates, contain at least $15 \%$ cocoa liquor, but may contain as much as $60 \%$, with the remainder being cocoa butter, sugar and other additives. Milk chocolates are the predominant form of chocolates consumed worldwide and typically contain 10-12\% cocoa liquor. In Malaysia, many different brands of the various chocolate types are available; however, no report has been published on phenolic and theobromine contents of these chocolates. More research is needed on phenolic and methylxanhine analysis of chocolate from different brands, varieties or matrices which can be used to include or update food composition databases. Therefore, the present study aimed to investigate the amount of phenolic and flavonoid contents includes catechin and epicatechin and theobromine content in dark, milk and white chocolates available in the local Malaysian marketplace. 


\section{Results and Discussion}

\section{Total phenolic and flavonoid contents}

Table 1 shows total phenolic content in different types of commercial chocolates. The total phenolic content in chocolates was in the range of $116-585 \mathrm{mg}$ catechin equivalent (CAE)/100 g. There was a significant difference in total phenolic content among different types of commercial chocolates $(\mathrm{p}<$ 0.05 ) as assessed by one-way ANOVA. The results obtained were in agreement with the study done by Grassi et al. [28], where $100 \mathrm{~g}$ of chocolate contained approximately $500 \mathrm{mg}$ of polyphenols. Dark chocolate exhibited the highest phenolic content followed by milk and white chocolates. According to Cooper et al. [29], the present of non-fat cocoa solid (NFCS) as an excellent marker to determine the present of total phenolic content. Normally NFCS was found at the highest concentration in dark chocolates. Thus, theoretically, the higher amount of NFCS indicated the higher phenolic content in the chocolates. Nevertheless, white chocolates contained cocoa butter with no cocoa liquor. Thus, it cannot be considered as true chocolate. Hence, phenolic content and its compounds in white chocolates are lower than other chocolates.

Table 1.Total phenolic and flavonoid contents in different types of commercial chocolates.

\begin{tabular}{ccc}
\hline Type of chocolate & $\begin{array}{c}\text { Total phenolic content } \\
\text { (mg CAE/100 g chocolate) }\end{array}$ & $\begin{array}{c}\text { Total flavonoid content } \\
\text { (mg CAE /100 g chocolate) }\end{array}$ \\
\hline Dark & $578.64 \pm 5.04$ & $28.30 \pm 1.92$ \\
Milk & $160.46 \pm 6.58$ & $13.48 \pm 1.54$ \\
White & $126.39 \pm 7.86$ & $7.70 \pm 0.55$ \\
\hline
\end{tabular}

Values are expressed as mean $\pm \mathrm{SD}$. All values are significant $(\mathrm{p}<0.05)$ different between samples.

The relative standard deviation was less than $11 \%$.

The flavonoid content was in the range of 7-29 $\mathrm{mg} \mathrm{CAE} / 100 \mathrm{~g}$ chocolate (Table 1). This amount was lower when compared to the results reported by Grassi et al. [28]. The total phenolic and flavonoid contents of milk chocolates were significantly lower than for dark chocolates. Natsume et al. [16] reported that the presence of milk in cocoa products may interfere with analyses for polyphenols due to the binding of the latter to proteins. Almost all of chocolates available in the market contained added milk. Generally, dark chocolates contain either no or small amounts of milk, while white chocolates had added milk powder or condensed milk.

The flavonoid content was in the same order as the phenolic content. The content was significantly different $(\mathrm{p}<0.05)$ among the studied commercial chocolates. A high correlation $(r=0.97)$ between total phenolic and flavonoid contents was observed (Figure 1). This may be attributed to catechin and epicatechin that are abundantly found in cocoa. According to Cooper et al. [29], epicatachin showed a strong correlation with other polyphenols, but the correlation between polyphenols and catechin was not high. The relationship suggests that whenever cocoa beans are processed into chocolates, these polyphenols were all affected to the same degree. 
Figure 1. The correlation between total phenolic and flavonoid contents.

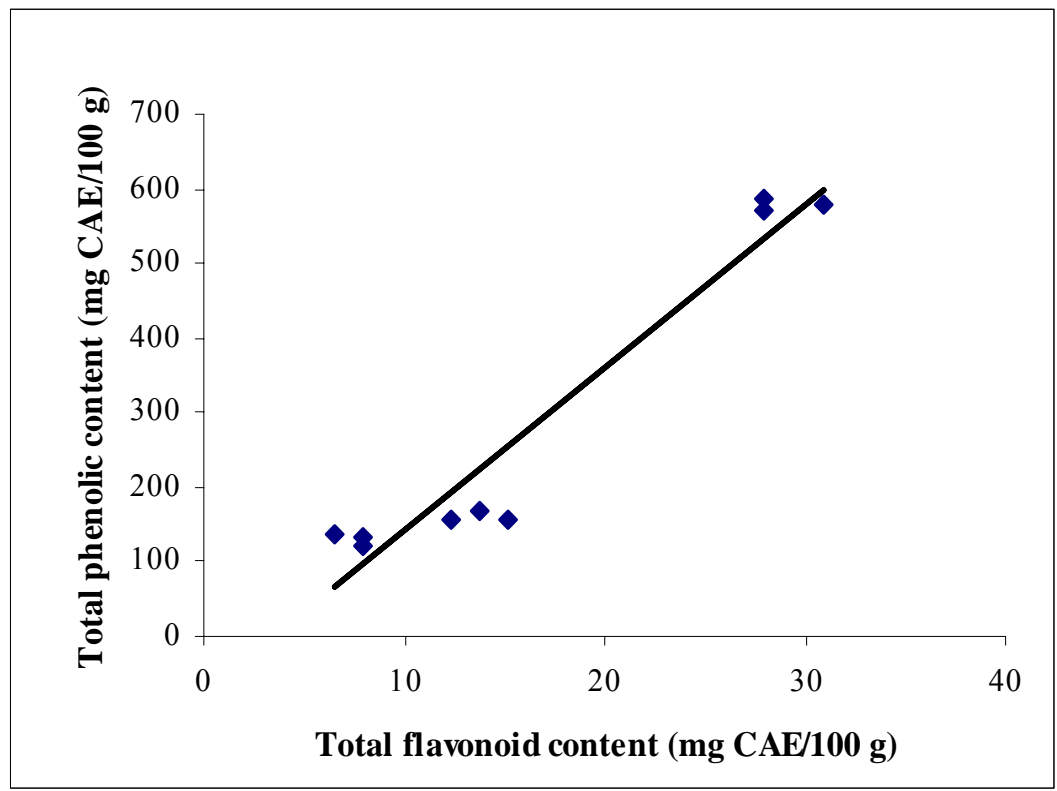

The polyphenol content in chocolates varies greatly depending on processing techniques such as fermentation of cocoa beans and alkalinization of cocoa powders [30, 14]. In addition, Cooper et al. [29] reported that the percentage of cocoa appears on the chocolates labeling cannot be used accurately to estimate the polyphenols concentration, since it includes polyphenol-free cocoa butter. This may overestimate the polyphenols concentration in particular chocolates. In fact, dietary polyphenols contain unlimited structure differences of carbon skeleton and oxidation state of the heterocyclic of flavonoids. This creates the difficulties in determination of polyphenols content.

Fermentation is an essential step for the development of suitable flavours and flavour precursors that last from five to six days. However, epicatechin and soluble polyphenol content are reduced to approximately 10 to $20 \%$, respectively, during fermentation [30]. This is not only due to oxidation processes, but is also caused by diffusion of polyphenols by sweating in fermentation [10, 31, 32]. Most beans for chocolate manufacture are fermented. Fermentation is one of the major steps that affect polyphenols content. Ecuadorian beans are normally fermented for three days and West African beans for five days. Between days two and three, epicatechin content is reported to decrease sharply, which could indicate that it is either consumed during the formation of larger tannins or lost due to water draining during fermentation [10].

According to $\mathrm{Gu}$ et al. [26], treatment with alkali influences the degradation of polyphenol compounds. Furthermore, Miller et al. [33] showed that alkalization reduced the antioxidant properties and flavonol content in cocoa powder. Most chocolates are produced using the alkalized cocoa powder, thus the content of polyphenols in chocolates had significant lower than in cocoa powder.

\section{Catechin and epicatechin contents}

Cocoa is reported to have high levels of antioxidant phenolics compared to tea [34]. Reversedphase high performance liquid chromatography (HPLC) was used to determine the concentration of catechin and epicatechin in commercial chocolate samples. The spiking procedure with a known 
amount of standard (catechin and epicatechin) was done to confirm the identity of individual peaks. The limit of detection (LOD) and limit of quantification (LOQ) for catechin and epicatechin were 0.01 and $0.03 \mathrm{mg} / \mathrm{mL}$, respectively. Catechin and epicatechin were detected in dark chocolate with $184.80 \pm$ 1.14 and $274.35 \pm 1.40 \mathrm{mg} / 100 \mathrm{~g}$ chocolate, respectively. These values were in agreement with the study by Gu et al. [26]. The present study found that the amounts of catechin and epicatechin in milk and white chocolates were below than 0.01 and $0.03 \mathrm{mg} / \mathrm{mL}$, respectively. Results indicate epicatechin was predominant in dark chocolates. As reported by Cooper et al. [27], the ratio between epicatechin to catechin is 1 to 0.11 . They also demonstrated that epicatechin content varies according to the manufacturing process due to epimerization of this compound to catechin.

\section{Methylxanthine contents}

The consumption of methylxanthines (caffeine, theobromine, and theophylline) and their potential physiological effects makes consumers desire to know the methylxanthine contents of foodstuffs. The present study found that theobromine could be found in dark and milk chocolates (Table 2). Theobromine levels were significantly higher in dark chocolates compared to milk chocolates, with $883.11 \pm 3.54$ and $125.54 \pm 0.98 \mathrm{mg}$ theobromine/100 $\mathrm{g}$ chocolate, respectively. The level of theobromine reported by Zoumas et al. [20] was similar with the results in the present study. However, Ramli et al. [24, 25] found no significant difference in the methylxanthine levels between Malaysian commercial dark and milk chocolates. The amount of theobromine in white chocolate was below than $0.05 \mathrm{mg} / \mathrm{mL}$ (the LOD and LOQ for theobromine were 0.02 and $0.05 \mathrm{mg} / \mathrm{mL}$, respectively). This was similar with the result obtained by Ministry of Agriculture, Fisheries, and Food (MAFF) [35], and may be due to the absence of added cocoa mass in white chocolate.

Table 2: Theobromine in different types of commercial chocolates.

\begin{tabular}{cc}
\hline Type of chocolate & $\mathbf{m g} / \mathbf{1 0 0} \mathbf{g}$ chocolate \\
\hline Dark & $883.11 \pm 3.54$ \\
Milk & $125.154 \pm 0.98$ \\
White & BDL \\
\hline
\end{tabular}

Values are expressed as mean \pm SD. Values are significant $(p<0.05)$ different between samples.

The relative standard deviation was $<1 \%$. BDL: Below detection limit.

Cocoa products are rich in caffeine and theobromine. Theobromine levels in chocolates was higher compared to other sources of methylxanthines such as carbonated beverages, coffee, and tea. However, methylxanthine-containing products such as chocolate chips, and milk chocolates, may not be accurately determined, as reported by Caudle et al. [36]. The present study showed that studied chocolates may contain little amounts of solid cocoa liquor/mass, which may lead to an underestimation of the methylxanthine content. According to Ministry of Agriculture, Fisheries, and Food (MAFF) [35], dark chocolates contained 237-519 mg of theobromine per $50 \mathrm{~g}$ portion. Michener and Rozin [37] reported that the main psychopharmacological active constituents of chocolates due to the present of high amount of methylxanthines in cocoa solid. The macronutrients (sugar and fat) did not significantly inhibit the uptake of methylxanthines in chocolates [19]. This indicated that, the 
effects of methylxanthines towards body systems remain the same even in dark, milk or white chocolates. Therefore, theobromine plays a significant role in reinforcing consumption of chocolates. They also reported that the psychopharmacological activity in chocolates to be confined to the combination of caffeine and theobromine. Since theobromine and caffeine always encounter together in cocoa products, thus, any behavioral effects following with cocoa consumption will depend on the quantity and bioavailability of methylxanthines [38].

\section{Conclusions}

Both total phenolic and flavonoid contents in studied commercial chocolates were in the order of dark chocolates $>$ milk chocolates $>$ white chocolates. This could be due to the addition of different amount cocoa liquor or mass into the chocolates manufacturing. The highest phenolic content in dark chocolates compare to milk and white chocolates due to higher cocoa mass content. White chocolates with no addition of cocoa mass have possessed low phenolics and flavonoids contents. Apart from total phenolic content, theobromine was also detected in dark and milk chocolates. This study indicated that dark chocolates had contained higher phenolic antioxidant compounds compared to the other studied chocolates.

\section{Experimental}

\section{Sample collection and preparation}

Three different types of chocolates namely dark, milk and white chocolate of various international and national brands were studied. For each type of chocolate a total of four national or international brands, representing commercial products available to customers, were randomly purchased from local markets in Kuala Lumpur, Malaysia. A composite sample was prepared from five samples of dark chocolates of the same brand, and the same preparation was also done for the milk and white chocolates. A total of 20 samples were analyzed for each chocolate type. The solid chocolates were chopped into small pieces and kept at $-20{ }^{\circ} \mathrm{C}$ before analysis.

\section{Chemicals}

Catechin, sodium carbonate $\left(\mathrm{Na}_{2} \mathrm{CO}_{3}\right)$, and sodium nitrite $\left(\mathrm{NaNO}_{2}\right)$ were purchased from Sigma Aldrich (St Louis, MO, USA). Folin-Ciocalteu reagent, acetone, and $n$-hexane were purchased from Merck (Darmstadt, Germany). Sodium hydroxide $(\mathrm{NaOH})$ was purchased from Hamburg Chemical (Heilbronn, Germany). Aluminum chloride $\left(\mathrm{AlCl}_{3}\right)$ was purchased from BDH Chemical (Poole, England). Other common reagents used were of HPLC grade otherwise stated.

\section{Sample extraction}

The samples extraction was according to the method used by Natsume et al. [16]. Samples of each type of chocolate $(10 \mathrm{~g})$ were triturated with $n$-hexane $(3 \times 50 \mathrm{~mL})$ at room temperature for $30 \mathrm{~min}$ in 
order to remove most of the fats. The defatted chocolate $(0.5 \mathrm{~g})$ was extracted with $80 \%(\mathrm{v} / \mathrm{v})$ acetone $\left(3 \times 50 \mathrm{~mL}\right.$ ) at $80{ }^{\circ} \mathrm{C}$, then the mixture was filtered through a filter paper (Whatman No. 1) using a Buchner funnel. This resulting solution was considered as polyphenol solution, which was used for polyphenols determination and HPLC analysis.

\section{Determination of total phenolic content}

The total phenolic content was determined according to the method of Lee et al. [34]. Briefly, appropriately diluted samples $(1 \mathrm{~mL})$ and a standard solution of catechin were transfer into a $25 \mathrm{~mL}$ volumetric flask containing distilled water $(9 \mathrm{~mL})$. A reagent blank using distilled water was also prepared. Folin-Ciocalteu phenol reagent $(1 \mathrm{~mL})$ was added to the mixture and been shaken. Following $5 \mathrm{~min}, 7 \%(\mathrm{w} / \mathrm{v}) \mathrm{Na}_{2} \mathrm{CO}_{3}$ solution $(10 \mathrm{~mL})$ was added with mixing. The solution was then immediately diluted to a volume of $25 \mathrm{~mL}$ with distilled water and was mixed thoroughly. After incubation for 90 min at room temperature, the absorbance relative to that of a prepared blank at $750 \mathrm{~nm}$ was measured using a UV-Vis spectrophotometer (SECOMAM, Anthelie Advanced 5, France). The phenolic content was calculated based on the catechin calibration curve with the concentration of $0.2,1,5,10,15$, and $20 \mu \mathrm{g} / \mathrm{mL}$. The total phenolic contents of the samples were expressed as milligrams catechin equivalents (CAE) per serving size.

\section{Determination of flavonoid content}

The flavonoid content was measured using a colorimetric assay developed by Zhishen et al. [39]. Briefly, appropriately diluted sample $(1 \mathrm{~mL})$ was placed in a $10 \mathrm{ml}$ volumetric flask containing distilled water $(4 \mathrm{~mL})$. At time zero, $5 \% \mathrm{NaNO}_{2}(0.3 \mathrm{~mL})$ was added to each volumetric flask; at 5 min, $10 \% \mathrm{AlCl}_{3}(0.03 \mathrm{~mL})$ was added; after $6 \mathrm{~min}, 1 \mathrm{M} \mathrm{NaOH}(2 \mathrm{~mL})$ was added. The mixture was then immediately diluted up to $10 \mathrm{~mL}$ with distilled water and was mixed thoroughly. The development of pink color was determined at $510 \mathrm{~nm}$ against blank. Catechin was used as the standard for a calibration curve. The flavonoid content was calculated using the linear equation based on the calibration curve with the concentration of $1,5,10,15$, and $20 \mu \mathrm{g} / \mathrm{mL}$. The flavonoid of the samples was expressed as milligrams catechin equivalents (CAE) per serving size.

Analysis of individual polyphenols and methylxanthines by reversed-phase high performance liquid chromatography (HPLC)

The determination of individual polyphenols (catechin and epicatechin) and methylxanthine (theobromine) were done according to the method described by Natsume et al. [16]. Ten microlitres of each polyphenol solution was analyzed on HPLC with a $\mathrm{C}_{18}$ column ( $250 \mathrm{~mm}$ x $4.6 \mathrm{~mm}$ I.D., $\left.5 \mu \mathrm{m}\right)$, by using the solvents (A): $0.1 \%$ trifluoroacetic acid in acetonitrile $\left(\mathrm{CH}_{3} \mathrm{CN}\right)$ and $(\mathrm{B}): 0.1 \%$ trifluoroacetic acid in water. Elution was done with a linear gradient of 0 to $10 \% \mathrm{~A}$ in $5 \mathrm{~min}, 10$ to $25 \% \mathrm{~A}$ in $25 \mathrm{~min}$, and 25 to $100 \% \mathrm{~A}$ in $6 \mathrm{~min}$ (flow rate at $0.8 \mathrm{~mL} / \mathrm{min}$ ). Catechin and epicatechin were used as the standard for calibration curves. The catechin and epicatechin content were calculated using the linear equation based on the calibration curve with the concentration of $100,200,300,400$, and $500 \mu \mathrm{g} / \mathrm{mL}$. 
The catechin and epicatechin contents of the samples were expressed as $\mathrm{mg} / 100 \mathrm{~g}$ sample. Theobromine contents were calculated based on the calibration curve with the concentration of 200, 250, 400 and $600 \mu \mathrm{g} / \mathrm{mL}$. The theobromine contents of the samples were expressed as $\mathrm{mg} / 100 \mathrm{~g}$ sample.

\section{Acknowledgements}

The authors would like to acknowledge the assistance of the laboratory staff from the Department of Nutrition and Dietetics, Faculty of Medicine and Health Sciences, Universiti Putra Malaysia.

\section{References}

1. Hertog, M.G.L.; Kromhout, D.; Aravanis, C.; Blackburn, H.; Buzina, R.; Fidanza, F.; Giampaoli, S.; Jansen, A.; Menotti, A.; Nedeljkovic, S.; Pekkarinen, M.; Simic, B.S.; Toshima, H.; Feskens, E.J.M.; Hollman, P.C.H.; Katan, M.B. Flavonoid intake and long-term risk of coronary heart disease and cancer in the seven countries study. Arch. Int. Med. 1995, 155, 381-386.

2. Knekt, P.; Jarvinen, R.; Reunanen, A.; Maatela, J. Flavonoid intake and coronary mortality in Finland: A cohort study. Brit. Med. J. 1996, 312, 478-481.

3. Amin, I.; Faizul, H.A.; Azli, R. Effect of cocoa powder extract on plasma glucose levels in hyperglycemic rats. Nutr. Food Sci. 2004, 34, 116-121.

4. Ruzaidi Azli, M.M.; Amin, I.; Nawalyah, A.G.; Hamid, M.; Faizul, H.A. The effect of Malaysian cocoa extract on glucose levels and lipid profiles in diabetic rats. J. Ethnopharmacol. 2005, 98, 55-60.

5. Ruzaidi Azli, M.M.; Abbe Maleyki, M.J.; Amin, I.; Nawalyah, A.G.; Muhajir, H. Protective effect of polyphenol-rich extract prepared from Malaysian cocoa (Theobroma cacao) on glucose levels and lipid profiles in streptozotocin-induced diabetic rats. J. Sci. Food Agric. 2008, 88, 1442-1447.

6. Abbe Maleyki, M.J.; Amin, I.; Chong, P.P.; Muhajir, H.; Syed Hasbullah, S.K. Effects of cocoa extract on glucometabolism, oxidative stress, and antioxidant enzymes in obese-diabetic (Ob-db) rats. J. Agric. Food Chem. 2008, 56, 7877-7884.

7. Taubert, D.; Roesen, R.; Schömig, E. Effect of cocoa and tea intake on blood pressure - A Metaanalysis. Arch. Intern. Med. 2007, 167, 626-634.

8. Giuseppe, D.R.; Castelnuovo, D.A.; Centritto, F.; Zito, F.; Curtis, D.A.; Costanzo, S.; Vohnout, B.; Sieri, S.; Krogh, V.; Donati, M.B.; Gaetano, D.G.; Iacoviello, L. Regular consumption of dark chocolate is associated with low serum concentrations of C-reactive protein in a healthy Italian population. J. Nutr. 2008, 138, 1939-1945.

9. Hammerstone, J.F., Lazarus, S.A., Mitchell, A.E., Rucker, R., Schmitz, H.H. Identification of procyanidins in cocoa (Theobroma cacao) and chocolate using high-perfomance liquid chromatography/ mass spectrometry. J. Agric. Food Chem. 1999, 47, 490-496.

10. Kim, H. and Keeney, P.G. (-)-Epicatechin content in fermented and unfermented cocoa beans. $J$. Food Sci. 1984, 49, 1090-1092.

11. Kelm, M.A.; Johnson, J.C.; Robbins, R.J.; Hammerstone, J.F.; Schmitz, H.H. High-performance liquid chromatography separation and purification of cacao (Theobroma cacao L.) procyanidins 
according to degree of polymerization using a diol stationary phase. J. Agric. Food Chem. 2006, 54, 1571-1576.

12. Tomas-Barberan, F.A.; Cienfuegos-Jovellanos, E.; Marin, A.; Muguerza, B.; Gil Izquierdo, A.; Cerdaa, B.; Zafrilla, P.; Morillas, J.; Mulero, J.; Ibarra, A.; Pasamar, M.; Ramoan, D.; Espin, J.C. A new process to develop a cocoa powder with higher flavonoid monomer content and enhanced bioavailability in healthy humans. J. Agric. Food Chem. 2007, 55, 3926-3935.

13. Rios, L.Y.; Gonthier, M.P.; Remesy, C.; Mila, I.; Lapierre, C.; Lazarus, S.A.; Williamson, G.; Scalbert, A. Chocolate intake increases urinary excretion of polyphenol-derived phenolic acids in healthy human subjects. Am. J. Clin. Nutr. 2003, 77, 912-918.

14. Adamson, G.E.; Lazarus, S.A.; Mitchell, A.E.; Prior, R.L.; Cao, G.; Jacobs, P.H.; Kremers, B.G.; Hammerstone, J.F.; Rucker, R.B.; Ritter, K.A.; Schmitz, H.H. HPLC method for the quantification of procyanidins in cocoa and chocolate samples and correlation to total antioxidant capacity. J. Agric. Food Chem. 1999, 47, 4184-4188.

15. Sanbongi, C.; Osakabe, N.; Natsume, M.; Takizawa, T.; Gomi, S.; Osawa, T. Antioxidative polyphenols isolated from Theobroma cacao. J. Agric. Food Chem. 1998, 46, 454-457.

16. Natsume, M.; Osakabe, N.; Yamagishi, M.; Takizawa, T.; Nakamura, T.; Miytake, H.; Hatano, T.; Yoshida, T. Analyses of polyphenols in cocoa liquor, cocoa, and chocolate by normal-phase and reversed-phase HPLC. Biosci. Biotechnol. Biochem. 2000, 64, 2581-2587.

17. Stavric, B. Methylxanthines: Toxicity to humans, theobromine, paraxanthine and the combined effects of methylxanthines. Food Chem. Toxicol. 1988, 26, 725-733.

18. Shively, C.A.; Tarka, S.M. Methylxanthine composition and consumption patterns of cocoa and chocolate products. Prog. Clin. Biol. Res. 1984, 158, 149-78.

19. Smit, H.J.; Gaffan, E.A.; Rogers, P.J. Methylxanthines are the psychopharmacologically active constituents of chocolate. Psychopharmacology 2004, 176, 412-419.

20. Zoumas, B.L.; Kreiser, W.E.; Martin, R.A. Theobromine and caffeine content of chocolate products. J. Food Sci. 1980, 45, 314-316.

21. Blauch, J.L.; Tarka, S.M. HPLC determination of caffeine and theobromine in coffee, tea, and instant hot cocoa mixes. J. Food Sci. 1983, 48, 745-747.

22. Craig, W.J.; Nguyen, T.T. Caffeine and theobromine levels in cocoa and carob products. J. Food Sci. 1984, 49, 302-303.

23. DeVries, J.W.; Johnson, K.D.; Heroff, J.C. HPLC determination of caffeine and theobromine content of various natural and red dutch cocoas. J. Food Sci. 1981, 46, 1968-1969.

24. Ramli, N.; Rahman, S.A.; Hassan, O.; Yatim, A.M.; Said, M.; Siang, L.L.; Fong, N.W. Caffeine and theobromine levels in chocolate couverture and coating products. Mal. J. Nutr. 2000, 6, 5563.

25. Ramli, N.; Yatim, A.M.; Said, M.; Heng, C.H. HPLC determination of methylxanthine and polyphenols levels in cocoa and chocolate products. Malay. J. Anal. Sci. 2001, 7, 377-386.

26. Gu, L.; House, S.E.; Wu, X.; Ou, B.; Prior, R.L. Procyanidin and catechin contents and antioxidant capacity of cocoa and chocolate products. J. Agric. Food Chem. 2006, 54, 4057-4061.

27. Cooper, K.A.; Campos-Gimenez, E.; Alvarez, D.J.; Nagy, K.; Donovan, J.L.; Williamson, G. Rapid reverse-phase ultra-performance liquid chromatography analysis of the major cocoa 
polyphenols and inter-relationship of their concentration in chocolates. J. Agric. Food Chem. 2007, 55, 2841-2847.

28. Grassi, D.; Lippi, C.; Necozione, S.; Desideri, G.; Ferri, C. Short-term administration of dark chocolate is followed by a significant increase in insulin sensitivity and a decrease in blood pressure in healthy persons. Am. J. Clin. Nutr. 2004, 81, 611-614.

29. Cooper, K.A.; Campos-Gimenez, C.; Alvarez, D.J.; Rytz, A.; Nagy, K.; Williamson, G. Predictive relationship between polyphenol and nonfat cocoa solids content of chocolate. J. Agric. Food Chem. 2008, 56, 260-265.

30. Wollgast, J.; Anklam, E. Review on polyphenols in Theobroma cacao: Changes in composition during the manufacture of chocolate and methodology for identification and quantification. Food Res. Int. 2000, 33, 423-447.

31. Bracco, U.; Grailhe, N.; Rostango, W.; Egli, R. Analytical evaluation of cocoa curing in the Ivory Coast. J. Sci. Food Agric. 1969, 20, 713-717.

32. Hansen, C.E.; del Olmo, M.; Burri, C. Enzyme activities in cocoa beans during fermentation. $J$. Sci. Food Agric. 1998, 77, 273-281.

33. Miller, K.B.; Hurst, W.J.; Payne, M.J.; Stuart, D.A.; Apgar, J.; Sweigart, D.S.; Ou, B. Impact of alkalization on the antioxidant and flavanol content of commercial cocoa powders J. Agric. Food Chem. 2008, 56, 8527-8533

34. Lee, K.W.; Kim, Y.J.; Lee, H.J.; Lee, C.Y. Cocoa has more phenolic phytochemicals and a higher antioxidant capacity than teas and red wine. J. Agric. Food Chem. 2003, 51, 7292-7295.

35. Ministry of Agriculture, Fisheries, and Food (MAFF). Survey of caffeine and other methylxanthines in energy drinks and other caffeine-containing products (updated). Food Surveillance Information Sheet 144, 1998.

36. Caudle, A.G.; Gu, Y.; Bell, L.N. Improved analysis of theobromine and caffeine in chocolate food products formulated with cocoa powder. Food Res. Int. 2001, 34, 599-603.

37. Michener, W.; Rozin, P. Pharmacological versus sensory factors in the satiation of chocolate craving. Physiol. Behav. 1994, 56, 419-422.

38. Mumford, G.K.; Benowitz, N.L.; Evans, S.M.; Kaminski, B.J.; Preston, K.L.; Sannerud, C.A.; Silverman, K.; Grifliths, R.R. Absorption rate of methylxanthines following capsules, cola and chocolate. Eur. J. Clin. Pharmacol. 1996, 51, 319-325.

39. Zhishen, J.; Mengcheng, T.; Jianming, W. The determination of flavonoid contents in mulberry and their scavenging effects on superoxide radicals. Food Chem. 1999, 64, 555-559.

Sample Availability: Samples are available from the authors.

(C) 2009 by the authors; licensee Molecular Diversity Preservation International, Basel, Switzerland. This article is an open-access article distributed under the terms and conditions of the Creative Commons Attribution license (http://creativecommons.org/licenses/by/3.0/). 